\title{
Oral vitamin E supplements can prevent the retinopathy of abetalipoproteinaemia
}

\author{
P RUNGE,' D P R MULleR, ${ }^{2}$ J McAllisteR, , D CALVER,$^{3}$ J K LLOYD,${ }^{4}$ \\ AND D TAYLOR ${ }^{12}$
}

From the 'Department of Ophthalmology, Hospital for Sick Children, London; the ${ }^{2}$ Department of Child Health, Institute of Child Health, London; the ${ }^{3}$ Department of Ophthalmology, Guy's Hospital, London; and the ${ }^{4}$ Department of Child Health, St George's Hospital Medical School, London

SUMMARY Six patients with abetalipoproteinaemia are described who received large doses of oral vitamin $\mathrm{E}$ for between 12 and 18 years in addition to a low fat diet and supplements of the other fat soluble vitamins. The progressive retinopathy observed in untreated abetalipoproteinaemia was substantially modified and most probably prevented by this therapy. Angioid streaks were noted in one patient. Treatment with vitamin A alone did not prevent or arrest the progression of the retinal lesion.

\begin{abstract}
Abetalipoproteinaemia is a rare inborn error of lipoprotein metabolism.' The clinical features were first described by Bassen and Kornzweig in $1950^{2}$ and comprise fat malabsorption, abnormally shaped red cells (acanthocytes), an ataxic neuropathy, and a retinopathy.
\end{abstract}

In 1960 three groups $^{3-5}$ independently demonstrated the total absence of beta (low density) lipoprotein from the plasma of affected patients. Subsequently it was shown that apoprotein B, the major apoprotein of low density lipoprotein, was undetectable. ${ }^{6}$ As a result of the absence of apoprotein B not only low density but also very low density lipoproteins and chylomicrons cannot be formed. The lack of these three lipoproteins results in greatly reduced concentrations of blood lipids.

The defective chylomicron formation causes accumulation of triglyceride within the mucosal cells of the small intestine and results in malabsorption of fat and the fat soluble vitamins. Vitamin $E$ is normally dependent on chylomicrons for absorption, and a major portion is transported by low density lipoprotein. In the absence of these lipoproteins vitamin $E$ is undetectable in the serum of patients with abetalipoproteinaemia. ${ }^{78}$ There is now good evidence to indicate that the neurological features of the condition can be prevented by large oral doses of

Correspondence to Mr D Taylor, FRCS, Department of Ophthalmology, Hospital for Sick Children, Great Ormond Street, London WC1N 3JH. vitamin E. ${ }^{9-11}$ This paper presents evidence from six patients with abetalipoproteinaemia which suggests that treatment with large oral doses of vitamin E can also prevent the development of the retinopathy.

\section{Patients and methods}

We have been following up eight patients with abetalipoproteinaemia for up to 24 years, and their treatment and progress have been reported previously. ${ }^{9-11}$ In all cases vitamin $\mathrm{E}$ was given orally in a dose of approximately $100 \mathrm{mg} / \mathrm{kg} /$ day. It varied from 47 to $172 \mathrm{mg} / \mathrm{kg} / \mathrm{day}$. This compares with a recommended dietary requirement of vitamin $E$ of 8-10 $\mathrm{mg} / \mathrm{day} .{ }^{12} \mathrm{The}$ adequacy of the vitamin $\mathrm{E}$ therapy was regularly assessed by measuring in vitro red cell haemolysis (either autohaemolysis or peroxide haemolysis) and serum vitamin $\mathrm{E}$ concentrations as described previously. ${ }^{8}$ The haemolysis returns to normal on therapy, and serum vitamin $E$ concentrations become detectable, though they do not reach the normal range because of the absence of low density lipoprotein.

In this study we report the detailed ophthalmological findings in six of the eight patients when they were recently re-examined. The other two patients were not available for study. The case numbers used in this report are the same as used previously. ${ }^{9-11}$

Cases $1,4,5,6$, and 7 were examined at the Hospital for Sick Children, Great Ormond Street, 
London, and the other patient (case 8 ) by Dr G J B Bedford at Ninewells Hospital and Medical School, Dundee. All patients had their corrected near and distance acuity measured, their colour vision tested with the City University and Ishihara plates, and their eye position and movement examined. The external eye examination included a slit-lamp examination. Visual fields were tested by either the tangent screen or the Goldmann perimeter depending on which was more applicable.

Electroretinograms were recorded by the technique described by Calver. ${ }^{13}$ A Medelec MS6 recording system with two-channel average was employed for the electroretinogram recording. The amplifiers had a band width of $0.16 \mathrm{~Hz}$ to $1.61 \mathrm{~Hz}$. A Medical Devices strobe was used with the strobe head positioned $30 \mathrm{~cm}$ from the eyes. All recordings were made with gold foil corneal electrodes and eight or 16 responses were averaged to ensure a clean trace. The pupils were dilated with $1 \%$ cyclopentolate. The electrodes were inserted and the initial recordings made with the lights on, and then after 2, 4, 6, and 8 minutes of dark adaptation. Further recordings were made with 10,20 , and $50 \mathrm{~Hz}$ flicker. A normal response for this apparatus is an amplitude of more than $150 \mu v$ from the major negative component (a wave) to the major positive component (b wave). Flicker responses should be present at all frequences.

\section{Results}

\section{PATIENT 1}

This 14-year-old girl was diagnosed as having abetalipoproteinaemia at the age of 1 month when examined for failure to thrive. Since that time she has received supplementary vitamins $A$ and $K$ and large doses of oral vitamin E. One sibling (not described in this report), had abetalipoproteinaemia.

Ophthalmoscopy was normal at the time of diagnosis and on reassessment in 1975, when she was 5 years old. Between the ages of 6 and 7 years her parents noticed that her left eye was 'turning in.' She had intermittent occlusion of the right eye and had worn spectacles since the age of 4 . On reassessment in 1981 she had no visual symptoms and no difficulty with night vision or with colour vision.

Visual acuity was $6 / 5(+3 \cdot 50+0 \cdot 50 \times 75)$ in the right eye and $6 / 9(+2 \cdot 50+0 \cdot 25 \times 90)$ in the left. Near vision was N5 in both eyes. Colour vision, tested with the Ishihara and City University plates, was normal in both eyes. A cover test showed a left alternating convergent squint of 15 dioptres for near and 10 dioptres for distance without glasses; with glasses it was 10 dioptres for near. External ocular movements were full. The pupils were equal and reacted normally to light and accommodation. Visual field exami-
Table 1 Electroretinograms of patients with abetalipoproteinaemia after long-term treatment with vitamin $E$

\begin{tabular}{lllllll}
\hline $\begin{array}{l}\text { Case } \\
\text { number* }\end{array}$ & $\begin{array}{l}\text { Right } \\
\text { eye } \\
\text { amplitude }\end{array}$ & $\begin{array}{l}\text { Left } \\
\text { eye } \\
\text { amplitude }\end{array}$ & \multicolumn{2}{l}{ Flicker } & & \multirow{2}{*}{ Result } \\
\cline { 3 - 6 } & & & & & & \\
\hline 1 & $230 \mu \mathrm{V}$ & $250 \mu \mathrm{V}$ & $\mathrm{X}$ & $\mathrm{X}$ & $\mathrm{X}$ & Normal \\
4 & $260 \mu \mathrm{V}$ & $240 \mu \mathrm{V}$ & $\mathrm{X}$ & $\mathrm{X}$ & $\mathrm{X}$ & Normal \\
5 & $175 \mu \mathrm{V}$ & $150 \mu \mathrm{V}$ & $\mathrm{X}$ & $\mathrm{X}$ & $\mathrm{X}$ & Normal \\
6 & $300 \mu \mathrm{V}$ & $300 \mu \mathrm{V}$ & $\mathrm{X}$ & $\mathrm{X}$ & $\mathrm{X}$ & Normal \\
7 & $190 \mu \mathrm{V}$ & $170 \mu \mathrm{V}$ & $\mathrm{X}$ & $\mathrm{X}$ & $\mathrm{X}$ & Normal \\
\hline
\end{tabular}

${ }^{*}$ Case numbers are the same as in previous reports. ${ }^{9-11}$

nation by tangent screen with a $2 \mathrm{~mm}$ white target at 1 metre was full. Slit-lamp examination was normal. Fundus examination with the pupils dilated showed healthy optic discs, maculae, and vessels. There was, however, a very slight suggestion of increased pigmentation in mid periphery. Electrodiagnostic studies were normal (Table 1).

\section{PATIENT 4}

This 13-year-old girl was diagnosed as having abetalipoproteinaemia at the age of 11 months when she presented with failure to thrive and steatorrhoea. She has been on supplementary vitamins $A$ and $K$ and large oral doses of vitamin $E$ since the time of diagnosis. Some irregularity of the pigment epithelium in both fundi was noted at the time of diagnosis, but it was thought to be normal for a fair haired baby. This appearance has remained unchanged. Visual field examination in 1979 when she was 8 years old was normal. The most recent reassessment was in 1981, at which time no visual symptoms were noted, and in particular there was no difficulty with night vision or in distinguished colours.

Examination in 1981 showed an unaided visual acuity of $6 / 5$ in the right eye, 6/6 in the left, and a near vision of $\mathrm{N} 5$ in both eyes. Visual field examination showed constriction to confrontation, and generalised constriction of Goldmann perimetry to 12 , I4, and II4 targets. Fundus examination showed only a diffuse pigmentary mottling in the equatorial region and a normal macular appearance (Fig. 1). Electrodiagnostic studies were normal (Table 1).

\section{PATIENT 5}

This 15-year-old girl presented at the age of 13 months with failure to thrive and steatorrhoea. She has been on supplementary vitamins $\mathrm{A}$ and $\mathrm{K}$ and large doses of oral vitamin $E$ since the age of 16 months. Ophthalmoscopy at the time of diagnosis was normal and remained so on reassessment in 1975 at the age of 7 years. At the age of 9 years she was 


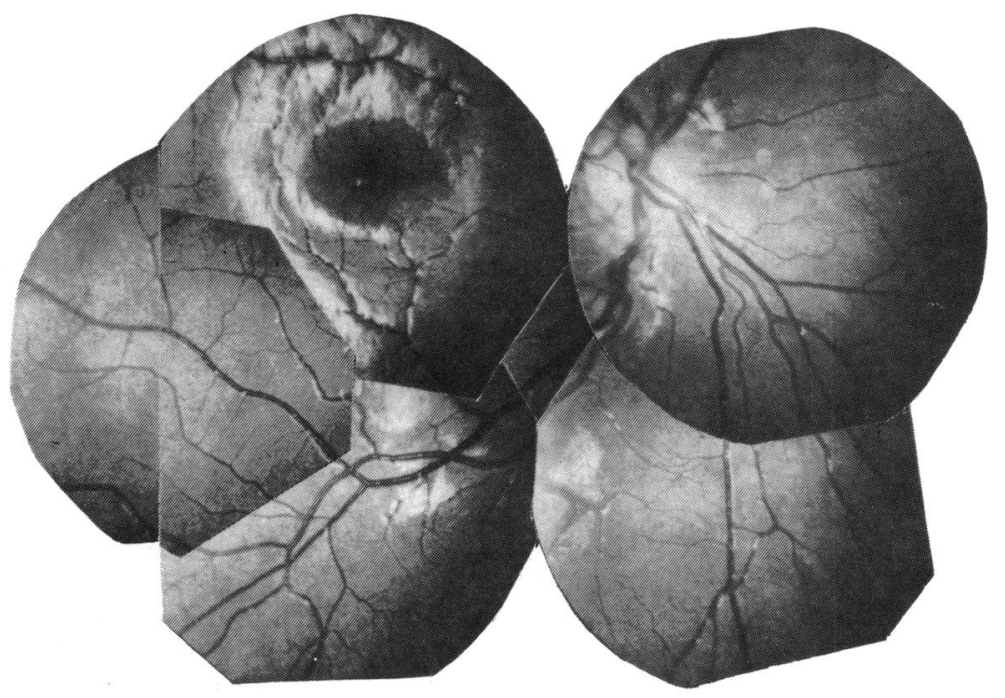

Fig. 1 Composite photographs of (A) right and (B) left fundi of patient 4. There are prominent light reflexes round the maculae and some vessels. Patients 1, 4, 5, and 6 all had fundi within normal limits.

Fig. 1A

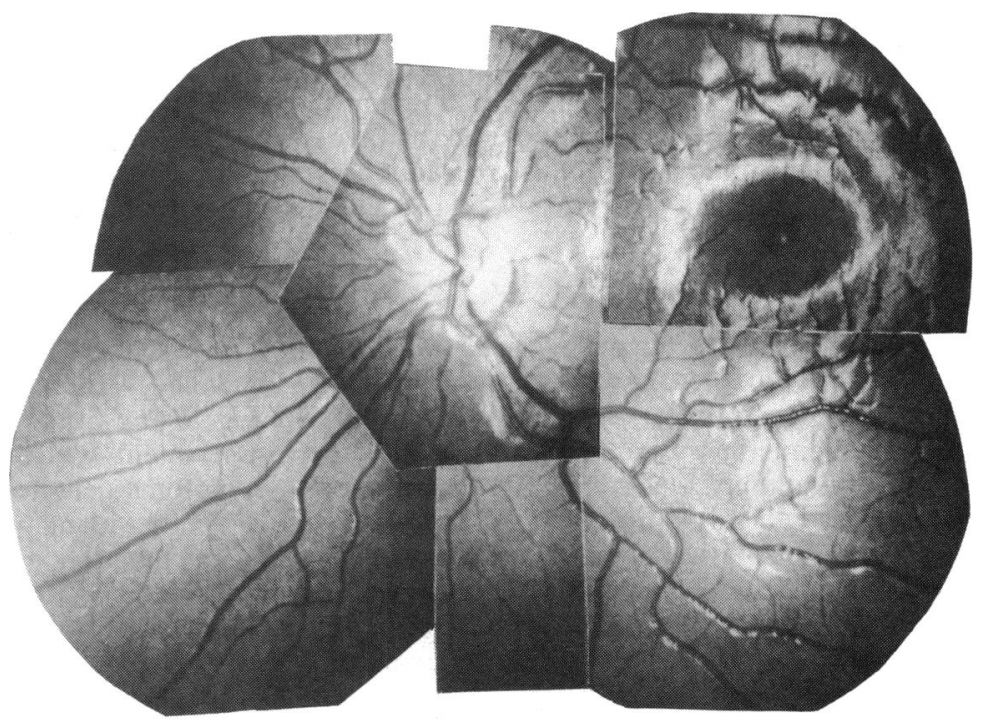

Fig. 1B

found to be myopic (there is a paternal family history of myopia) and she was prescribed spectacles. On reassessment in 1981 she had no visual symptoms apart from her myopia, which was fully correctable. She had no difficulty with night vision or in distinguishing colours.

Examination in July 1981 showed a corrected visual acuity of $6 / 5(-2 \cdot 0)$ right eye and $6 / 5(-2.00$ $-0.25 \times 70)$ left eye and a near vision of N5 in both eyes. Visual fields were full to a $2 \mathrm{~mm}$ white target at 1 metre. Fundus examination showed healthy optic discs, maculae, and vessels and no abnormal pigmentation. Electrodiagnostic studies were within the normal range as shown in Table 1.

PATIENT 6

This 20-year-old man's abetalipoproteinaemia was diagnosed at the age of 19 months after he presented with failure to thrive. He has been on supplementary vitamins $A$ and $K$ and large oral doses of vitamin $E$ 


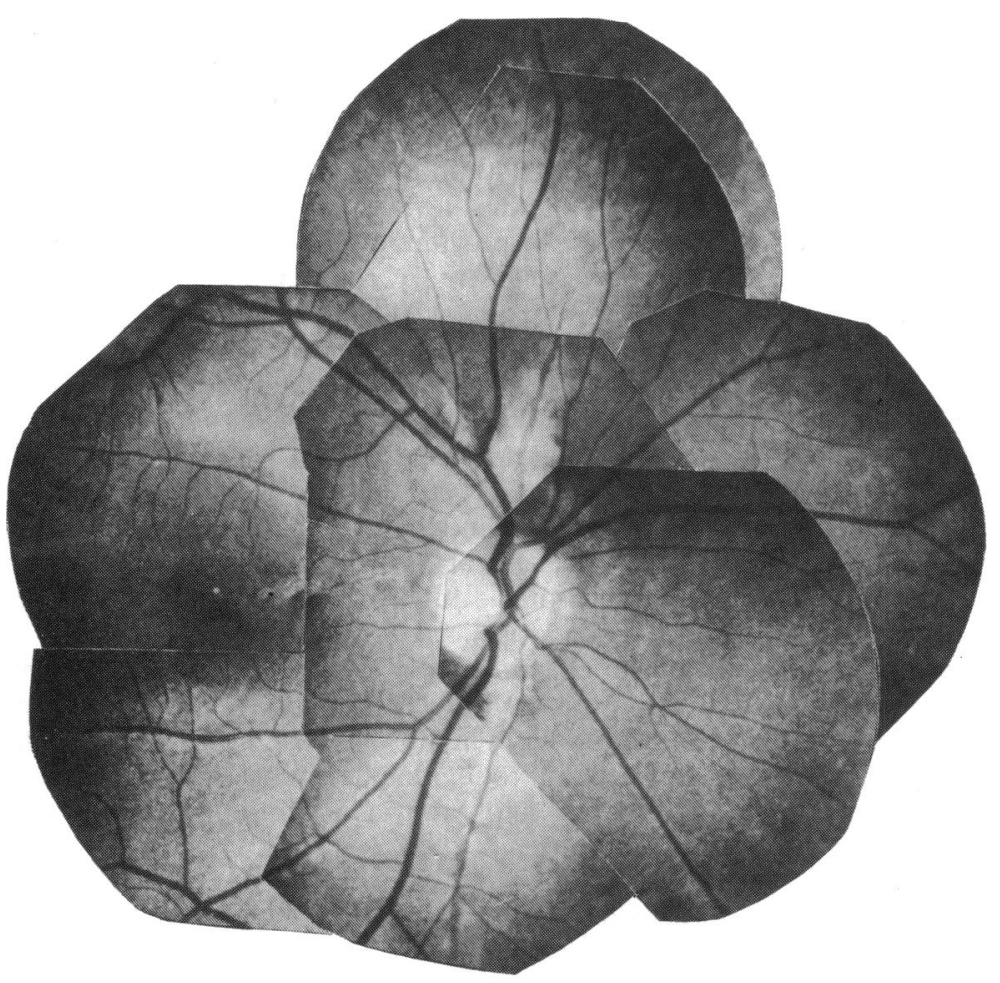

Fig. 2 Composite photographs of (A) right and (B) left fundi of patient 7 .

Fig. 2A

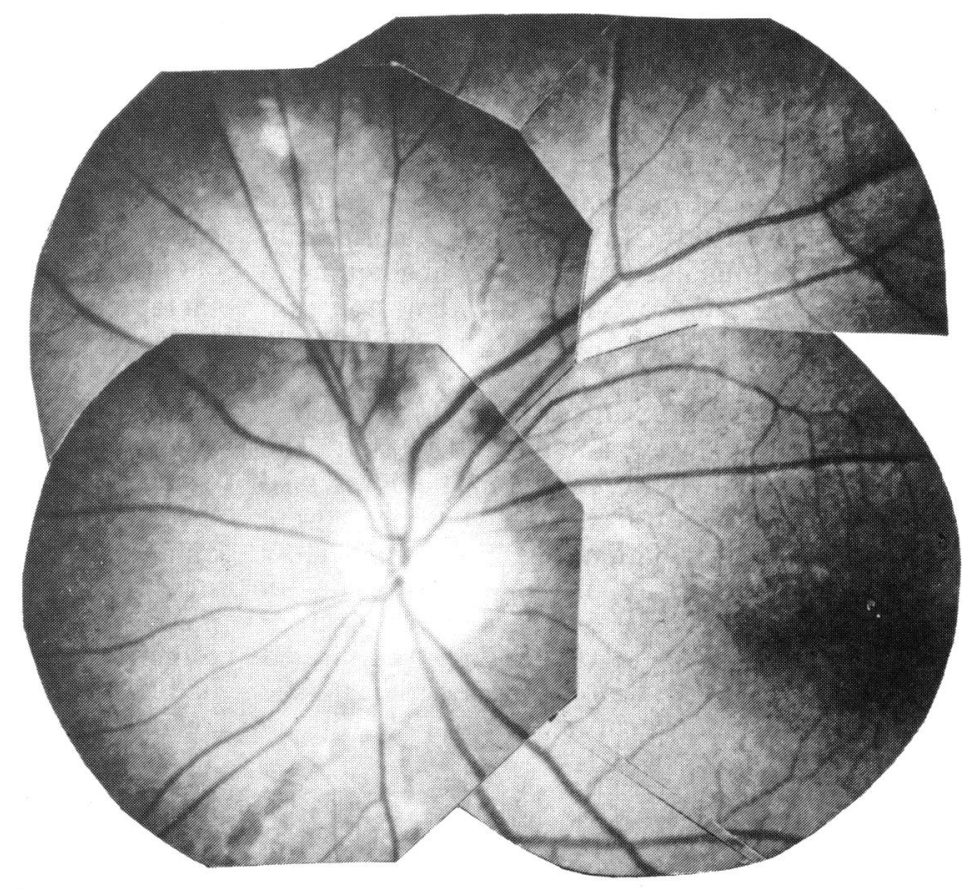

Fig. 2B 
since the age of 3 years 5 months. Ophthalmoscopy at the time of diagnosis was normal, and visual fields and electrodiagnostic tests were also normal. On reassessment in 1981 (aged 17 years) he had no visual symptoms, with no difficulty in night vision or in distinguishing colours.

On examination the unaided visual acuity was $6 / 5$ in the right eye and 6/4 in the left. Near vision was N5 in both eyes. Visual fields, tested by a tangent screen, were full to a $2 \mathrm{~mm}$ white target at 1 metre. Fundus examination showed healthy optic discs, maculae, and vessels, and normal pigmentation. Electrodiagnostic studies were normal (Table 1).

\section{PATIENT 7}

This 26-year-old woman is the original patient described by Salt and colleagues in $1960^{5}$ and her condition was diagnosed at the age of 17 months, when she presented with failure to thrive and steatorrhoea. Her parents had reduced serum lipid and low density lipoprotein concentrations. She therefore probably has homozygous hypobetalipoproteinaemia, which is inherited as an autosomal dominant, ${ }^{10}$ rather than classical abetalipoproteinaemia. The two conditions appear to be clinically and biochemically indistinguishable. The only relevant family history of ocular disease was glaucoma in a parental grandfather. She received supplementary vitamins $\mathrm{A}$ and $\mathrm{K}$ from diagnosis, ${ }^{5}$ but despite normal serum vitamin A concentrations she developed at the age of 5 years a slight pigmentary retinopathy in both eyes with minimal diminution of dark adaptation. She has been receiving large oral doses of vitamin $E$ since the age of 7 years 9 months. On reassessment in 1975, when she was 17, there had been no increase in pigmentation, and all electrodiagnostic tests of retinal function were normal. In July 1981 she complained of difficulty in adapting to subdued lighting but drove at night with no apparent problems. She had not noticed any difficulty in distinguishing colours.

On examination in 1984 the corrected visual acuity was $6 / 6(-1.00)$ right eye and $6 / 6(-1.00)$ left. The near vision was $\mathrm{N} 5$ in both eyes. Visual fields assessed by Goldmann perimetry (I2 and I4 targets) were normal. Fundus examination (Fig. 2) showed healthy optic discs, angioid streaks, and pigmentation at both maculae and in the far periphery. The vessels were normal. Fluorescein angiography (Fig. 3) confirmed the presence of angioid streaks. Electrodiagnostic studies which were normal are shown in Table 1.

\section{PATIENT 8}

This 28-year-old man's condition was diagnosed at the age of 7 years 3 months, but large oral doses of vitamin $\mathrm{E}$ were not given until he was 10 years 3 months. He had been receiving vitamin $E$ supplements prior to diagnosis, and the dosage was subsequently increased. The progression of his neurological and ophthalmological signs and symptoms while he was on vitamin A treatment alone has been noted in previous reports. ${ }^{914}$ At the time of diagnosis a pigmentary retinopathy involving the periphery was observed. Just before he began the vitamin supplements his electro-oculogram was flat. Four years later it showed a light rise of $170 \%$ in the right eye and $165 \%$ in the left, and by the age of 17 years the values were normal at $248 \%$ and $200 \%$ in the right and left eyes respectively. A bilaterally normal electroretinogram was also recorded in 1973 (at age 17 years) at Moorfields Eye Hospital. The appearance of the fundi has not changed since the time of diagnosis.

Ocular examination in 1981, when he was 25 years old, showed a corrected visual acuity of $6 / 9$ in the right eye and $6 / 18$ in the left. Testing of colour vision showed a mild red-green defect on Ishihara testing. The electroretinogram was within normal limits for the laboratory.

\section{Discussion}

The six patients reported on here have all been treated with large oral doses of vitamin $\mathrm{E}$ (approximately $100 \mathrm{mg} / \mathrm{kg} /$ day) for periods ranging from 12 to 18 years. This was in addition to their receiving a low fat diet and supplements of the other fat soluble vitamins. ${ }^{15}$ The long term results of ocular function in these patients show that the normally progressive retinal changes initially described by Bassen and Kornzweig ${ }^{2}$ and which typically lead to blindness by early adult life have been avoided.

Over the prolonged time period of vitamin E therapy the compliance of case 1 was erratic but adequate as judged by in-vitro red cell haemolysis. In case 8 it was good until he left home, when it deteriorated and required close domiciliary supervision. The compliance in cases $4,5,6$, and 7 was excellent.

Patients 1, 5, and 6 developed no significant ophthalmological abnormality. Patient 4 had constriction of the visual fields and mild diffuse pigmentary mottling in the equatorial region of the retina, but the ERG remained normal. Cases 7 and 8 had retinal lesions while receiving vitamin $\mathrm{A}$ alone, but the progression of these features was arrested after treatment with large oral doses of vitamin $E$.

Angioid streaks were observed in the fundi of patient 7. These streaks are breaks in Bruch's membrane, ${ }^{1617}$ which are usually found either in isolation or associated with pseudoxanthoma elas- 


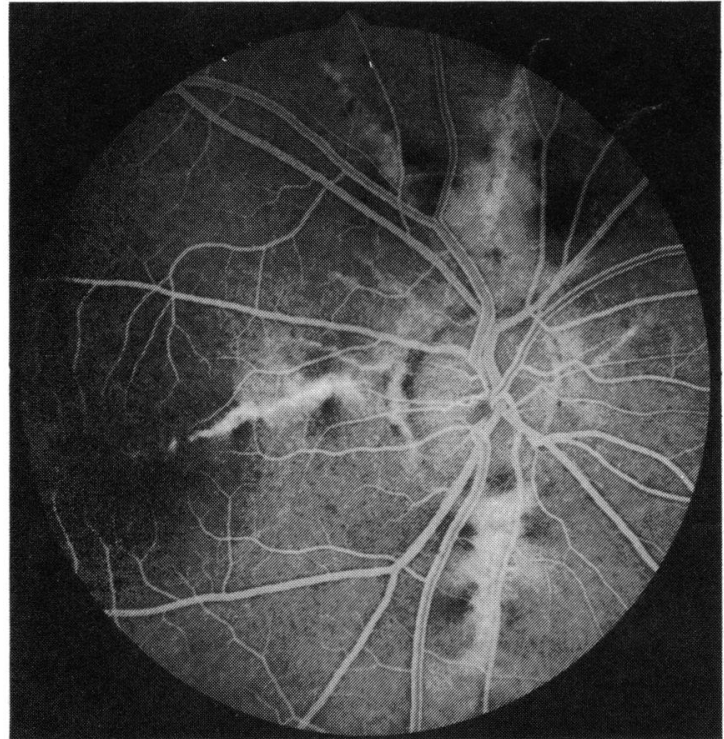

Fig. 3A

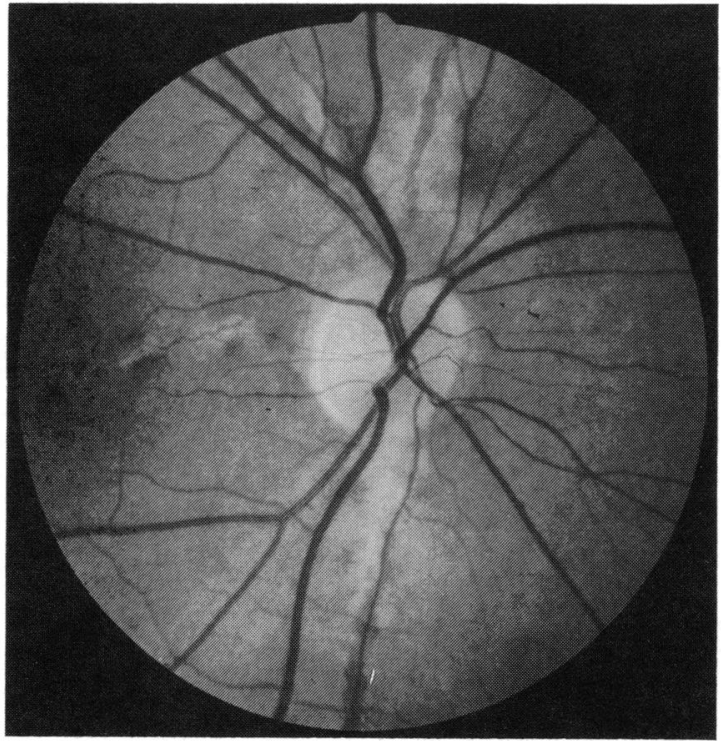

Fig. 3C

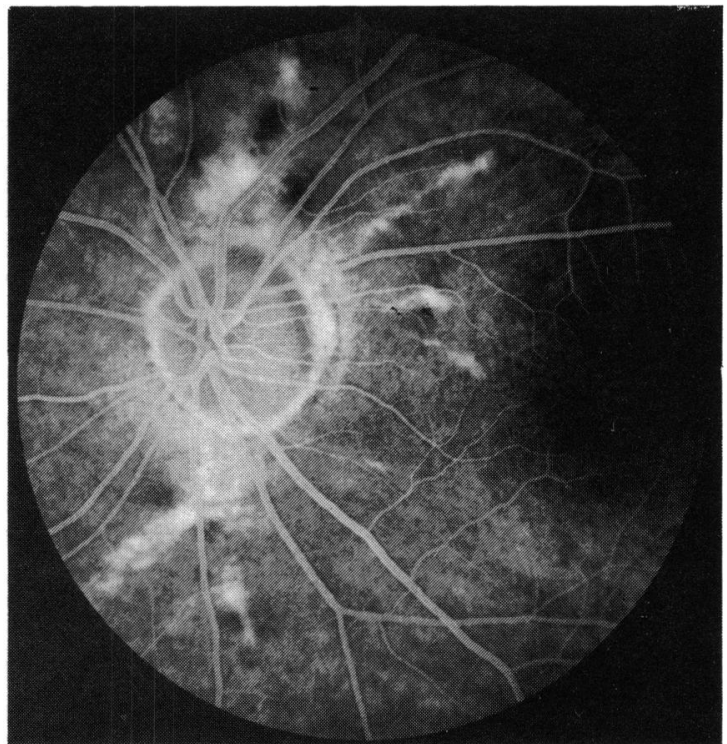

Fig. 3B

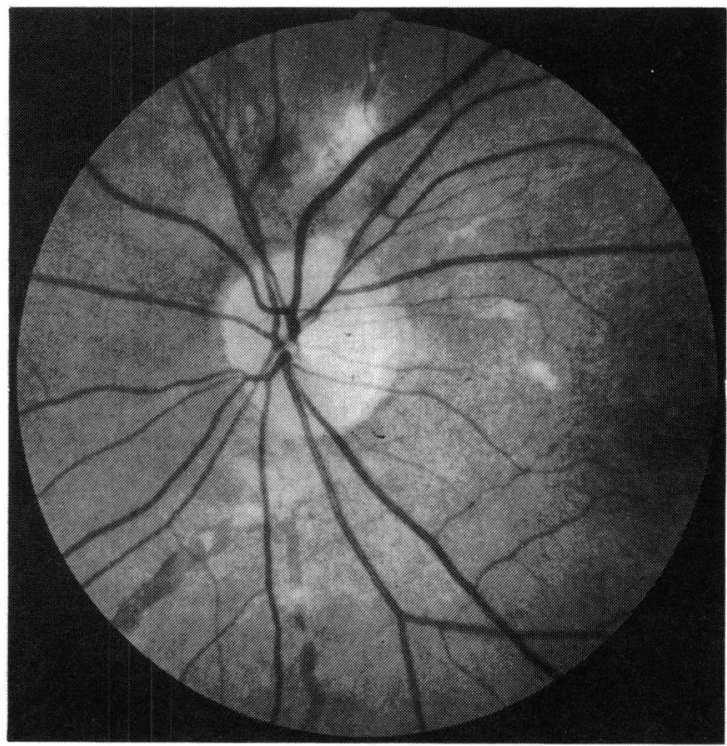

Fig. 3D

Fig. 3 Fluorescein angiograms of the fundi of patient 7. (A) Right fundus and (B) left fundus; (C) and (D) are corresponding fundal photographs.

ticum, Paget's disease of bone, sickle cell disease, betathalassaemia major, ${ }^{18}$ or hereditary spherocytosis. ${ }^{19}$ Their significance in this patient remains obscure. The occurrence of angioid streaks in several disorders with deformity of the red blood corpuscles is interesting and may reflect a common disease process, such as increased haemolysis with iron deposition in Bruch's membrane or a defect in the structure of Bruch's membrane as a result of a common genetic defect.

There are reports of improvement in both visual signs and symptoms when patients with abetalipoproteinaemia are treated with both vitamins $A$ and $E^{2021}$ and with vitamin $A$ alone. ${ }^{22}{ }^{23}$ The latter two 
groups agreed that improvement with vitamin $\mathrm{E}$ occurred only in less severely affected individuals. Others, however, have reported progression of the retinal changes in patients who have been receiving sufficient vitamin A to maintain normal serum concentrations (Wolff et al..$^{24}$ reporting case 7 of the present series and Bohlmann et al. ${ }^{25}$ Similar observations have recently been reported in a group of children with severe vitamin E deficiency secondary to chronic cholestasis who had clinical and electrophysiological evidence of retinal dysfunction despite most of them having normal serum vitamin A concentrations. ${ }^{26}$ Howard and colleagues ${ }^{27}$ reported on a man who had multiple resections for Crohn's disease, chronic steatorrhoea, and trace concentrations of serum vitamin $E$ who developed ataxia and a visual field defect with pigmentary degeneration of the retina. Vitamin $E$ therapy over a two-year period corrected both the visual field defect and ataxia. Further evidence for a role of vitamin E deficiency in the pathogenesis of the retinal lesions comes from studies on monkeys, ${ }^{28}$ rats, ${ }^{29}$ and dogs. ${ }^{30}$ All these investigations showed that an experimental deficiency of vitamin $E$ resulted in retinal degeneration. Robison. et al. ${ }^{29}$ also examined the interrelationship between vitamins $A$ and $E$ and found that a combined deficiency resulted in a synergistically deleterious effect on the retina of rats.

The mode of action of vitamin $\mathrm{E}$ in the retina is poorly understood. Vitamin $\mathrm{E}$ is an antioxidant which can scavenge free radicals and thus protect membrane lipids from peroxidation. It is normally present in high concentrations in the membranes of rod outer segments of the retina, ${ }^{31}$ an area which is particularly susceptible to peroxidation. This is because it contains high concentrations of polyunsaturated fatty acids,${ }^{32}$ is exposed to a plentiful supply of oxygen, and light is known to enhance peroxidation ${ }^{33} \mathrm{~A}$ deficiency of vitamin $\mathrm{E}$ is therefore likely to accentuate peroxidative damage to the retina and also increase oxidative destruction of vitamin E. ${ }^{29}$

It would appear from the long term studies in these six patients with abetalipoproteinaemia that supplementation with very large doses of vitamin $E$ can prevent the associated retinal as well as the neurological lesions. We therefore recommend that the vitamin $\mathrm{E}$ status of patients with chronic and severe fat malabsorption should be investigated and vitamin $E$ therapy instituted in order to achieve and maintain normal serum vitamin $E$ concentrations. The vitamin $E$ status of patients with unexplained retinal dystrophies should also be examined.

We give special thanks to Martin Johns and the Photographic Department at the Hospital for Sick Children, Great Ormond Street, London, for their assistance in preparing the figures for this article. DPRM thanks Hoffmann-La Roche for their continuing support.
This study was generously supported by a grant from the British Retinitis Pigmentosa Society.

\section{References}

1 Herbert PN, Assmann G, Gotto Jr AM, Fredrickson DS. Familial lipoprotein deficiency: abetalipoproeteinaemia, hypobetaliproteinaemia and Tangier disease. In: Stanbury JB, Wyngaarden JB, Fredrickson DS, Goldstein JL, Brown MS, eds. The metabolic basis of inherited disease. New York: McGrawHill, 1983: 589-621.

2 Bassen FA, Kornzweig AL. Malformation of the erythrocytes in a case of atypical retinitis pigmentosa. Blood $1950 ; 5: 381-7$.

3 Lamy M, Frezal J, Polonovski J, Rey J. L'absence congénitale de beta-lipoproteines. CR Soc Biol (Paris) 1960; 154: 1974-8.

4 Mabry CC, DiGeorge AM, Auerbach VH. Studies concerning the defect in a patient with acanthocytosis. Clin Res 1960; 8: 371-8.

5 Salt HB, Wolff OH, Lloyd JK, Fosbrooke AS, Cameron AH, Hubble DV. On having no beta-lipoprotein; a syndrome comprising a-beta-lipoproteinaemia, acanthocytosis and steatorrhoea. Lancet 1960; ii: 325-39.

6 Gotto AM, Levy RI, John K, Fredrickson DS. On the protein defect in abetalipoproteinaemia. $N$ Engl J Med 1971; 284: 813-5.

7 Kayden HJ, Silber R, Kossmann CE. The role of vitamin E deficiency in the abnormal autohemolysis of acanthocytosis. Trans Assoc AM Physician 1965; 78: 334-8.

8 Muller DPR, Harries JT, Lloyd JK. The relative importance of the factors involved in the absorption of vitamin $\mathrm{E}$ in children. Gut 1974; 15: 966-71.

9 Muller DPR, Lloyd JK, Bird AC. Long term management of abetalipoproteinaemia. Possible role for vitamin E. Arch Dis Child 1977; 52: 209-14.

10 Muller DPR, Lloyd JK. Effect of large oral doses of vitamin E on the neurological sequelae of patients with abetalipoproteinaemia. Ann NY Acad Sci 1982; 393: 133-40.

11 Muller DPR, Lloyd JK, Wolff $\mathrm{OH}$. Vitamin E and neurological function. Lancet 1983; i: 225-7.

12 Food and Nutrition Board, National Research Council. Recommended dietary allowances. 9th revised ed. Washington DC: National Academy of Science, 1980: 66-8.

13 Calver DM. Further electrodiagnostic assessment. In: Wybar KC, Taylor D, eds. Pediatric ophthalmology. New York: Dekker, 1983: 19-35.

14 Forsyth CC, Lloyd JK, Fosbrooke AS. A-beta-lipoproteinaemia. Arch Dis Child 1965; 40: 47-52.

15 Lloyd JK, Muller DPR. Management of abetalipoproteinaemia in childhood. In: Peeters H, ed. Protides of the biological fluids. Oxford and New York: Pergamon Press, 1978: 331-5.

16 Kofler A. Beitrage zur Kenntis dir angioid streaks (Knapp). Arch Augenheilkd 1917; 82: 134-49.

17 Clarkson JG, Altman RD. Angioid streaks. Surv Ophthalmol 1982; 26: 235-46.

18 Gibson JM, Chaudhuri PR, Rosenthal AR. Angioid streaks in a case of beta thalassaemia major. Br J Ophthalmol 1983; 67: 29-32.

19 McLane NJ, Grizzard WS, Kousseff GB, Hartmann RC, Serer RJ. Angiod streaks associated with hereditary spherocytosis. Am J Ophthalmol 1984; 97 : 444-54.

20 Azizi E, Zaidman JL, Eshchar J, Szeinberg A. Abetalipoproteinaemia treated with parenteral and oral vitamins $A$ and $E$ and with medium chain triglycerides. Acta Paediatr Scand 1978; 67: 797-801.

21 Bishara S, Merin S, Cooper M, Azizi E, Delpre G, Deckelbaum $R J$. Combined vitamin $A$ and $E$ therapy prevents retinal electrophysiological deterioration in abetalipoproteinaemia. Br $J$ Ophthalmol 1982; 66: 767-70.

22 Gouras P, Carr RE, Gunkel RD. Retinitis pigmentosa in abetalipoproteinaemia. Effects of vitamin A. Invest Ophthalmol 1971; 10: 784-93. 
23 Sperling MA, Hiles DA, Kennerdell JS. Electroretinographic responses following vitamin $\mathrm{A}$ therapy in a-beta-lipoproteinaemia. Am J Ophthalinol 1972; 73:342-51.

24 Wolff OH, Lloyd JK, Tonks EL. A-beta-lipoproteinaemia with special reference to the visual defect. Exp Eye Res 1964; 3: 439-42.

25 Bohlmann HE, Thiede H, Rosenstiel K. Abetalipoproteinamie bei drei Geschwistern. Dtsch Med Wochenschr 1972; 97: $892-6$.

26 Alvarez F, Llandrieu $\mathrm{P}$, Laget $\mathrm{P}$, Lemonnier F, Odievre $\mathrm{M}$, Alagille D. Nervous and ocular disorders in children with cholestasis and vitamin A and E deficiencies. Hepatology 1983; 3: 410-6.

27 Howard L, Ovesen L, Satya-Murti S, Chu R. Reversible neurological symptoms caused by vitamin $\mathrm{E}$ deficiency in patients with short bowel syndrome. Am J Clin Nutr 1982; 36: 1243-9.
28 Hayes KC. Retinal degeneration in monkeys induced by deficiencies of vitamin E or A. Invest Ophthalmol Vis Sci 1974; 13: 499-519.

29 Robison WB, Kuwabara T, Bieri JG. Deficiencies of vitamins E and $A$ in the rat. Retinal damage and lipofuscin accumulation. Invest Ophthalmol Vis Sci 1980; 19: 1030-7.

30 Riis RC, Sheffy BE, Loew E, Kern TJ, Smith JS. Vitamin E deficiency retinopathy in dogs. Am J Vet Res 1981; 42: 74-9.

31 Dilley RA, McConnell DG. Alpha-tocopherol in the retinal outer segment of bovine eyes. J Membr Biol 1970; 2: 317-22.

32 Daemen FJM. Vertebrate rod outer segment membranes. Biochim Biophys Acta 1973; 300: 255-65.

33 Feeney L, Berman ER. Oxygen toxicity: membrane damage by free radicals. Invest Ophthalmol Vis Sci 1976; 15: 789-91.

Accepted for publication 2 July 1985. 